\title{
Comparison of Knee Proprioception during the Three Trimesters of Pregnancy
}

\author{
Dr Deepa Abichandani ${ }^{1}$, Dr Vanshika Gupta ${ }^{2}$ \\ ${ }^{1}$ Assistant Professor, School of Physiotherapy, D.Y.Patil University, Navi Mumbai, India \\ ${ }^{2}$ Physiotherapist
}

\begin{abstract}
Background: Proprioception is seen to decline during pregnancy. Purpose: To compare knee joint proprioception during three trimesters of pregnancy. Methods: 36 pregnant women, 12 from each trimester, from Obstetric and Gynecological OPD of D.Y Patil Hospital, Navi Mumbai. Proprioception was assessed with digital inclinometer. Results: There was statistical significant difference of 2.75 between $1^{\text {st }}$ and $2^{\text {nd }}$ trimester and 2.48 between $1^{\text {st }}$ and $3^{\text {rd }}$ trimester at 30 degree knee flexion. While statistically significant difference of 2.82 was between $1^{\text {st }}$ and $2^{\text {nd }}$ trimester at 60 degree knee flexion. Conclusion: Knee joint position sense was found to decline over three trimesters of pregnancy.
\end{abstract}

Keywords: Proprioception, Pregnancy, Trimesters, Knee joint, Inclinotrac

\section{Introduction}

Proprioception is defined as the cumulative neural input to the Central Nervous System from specialized nerve endings called mechanoreceptors that are located in the joints, capsule, ligaments muscles, tendons and skin. ${ }^{1,2}$ The Central Nervous System (CNS) is the primary mediator for the perception and execution of musculoskeletal control and movement. ${ }^{1,3} \square$ Proprioception provides information regarding joint position sense, kinesthesia and perception of forces, hence it is an important component of the sensory motor system. ${ }^{1-5}$ Proprioception refers specially to conscious and unconscious appreciation of joint position, kinesthesia and perception of force. These signals are transmitted to the spinal cord via afferent (sensory) pathways. Conscious awareness of joint motion, position and force is essential for motor learning and the anticipation of movements, while unconscious proprioception modulates muscle function and initiates reflex mobilization. Proprioception helps to provide smooth coordinated movements, maintain normal body posture, regulate balance \& postural control. ${ }^{1,2}$

Pregnancy is the state of carrying a developing embryo or foetus within the female body consisting of three trimesters that see a woman's body undergoing various changes during pregnancy which include weight gain, changes in posture, and joint and ligament laxity along with changes in musculotendinous strength. ${ }^{6,7}$

Studies have shown that during pregnancy, joint laxity increases owing to hormonal fluctuation. It has been seen that during pregnancy, relaxin peaks during the first trimester and subsequently peripheral joint laxity occurs ${ }^{8,9}$ It was seen that knee laxity increased on an average of $105 \%, 128 \%$ \& $170 \%$ during the first, second \& third trimesters of pregnancy respectively. Researchers have also suggested that Estrogen and Relaxin have an effect on the neuromuscular system and the mechanics of soft tissues such as ligaments and tendons. ${ }^{1}$ A fall rate of $27 \%$ was reported during pregnancy especially during third trimester due to a decline in the balancing ability, which persists even after six to eight weeks after delivery. ${ }^{10,11}$
Previous studies in the past have compared ankle proprioception between pregnant \& non pregnant women, studied the impact of pregnancy on lumbar proprioception, assessed knee joint stiffness and proprioception during pregnancy but to the authors best knowledge there exists no study that has focused on knee joint proprioception with the progression of pregnancy.

Even though the balance issues and the visual reliance have been recorded in the pregnant women, the loss of proprioception in them has not been studied. Hence the purpose of our study was to compare the knee joint proprioception during the three trimesters of pregnancy.

\section{Aim and Objective}

To compare Knee Proprioception in the Three Trimesters of Pregnancy by assessing proprioception among pregnant women in their first, second and third trimester.

\section{Review of Literature}

1) A study was conducted by Preetha R \& John SM on Comparison of Ankle Proprioception Between Pregnant and Non Pregnant Women in 2011. 30 pregnant \& 30 non-pregnant women took part in the study. Their ankles were moved 10 times in dorsiflexion \& plantarflexion, $\&$ then placed at a particular angle. The subjects were then asked to move their ankle 10 times \& reproduce the target angle. A digital camera placed $60 \mathrm{~cm}$ away from the feet of the subject determined the error of the angle. It was found that the median repositioning error in the pregnant group was 11.6 degrees and the median repositioning error in the non-pregnant group was 4.2 degrees.

2) T. Banyai, A. Hagaet al, performed a study on Knee Joint Stiffness \& Proprioception during Pregnancy. This study was conducted in 2008 in Szeged. 22 pregnant \& 18 non pregnant women took part in the study that measured arthrometry, stabilometry\& position of knee joints. The study detected increased weakness of knees \& weaker proprioceptive perception of the anterior- 


\section{International Journal of Science and Research (IJSR) \\ ISSN (Online): 2319-7064}

Index Copernicus Value (2013): 6.14 | Impact Factor (2015): 6.391

posterior direction amongst pregnant women, explaining a higher risk of ACL injuries amongst pregnant women.

3) A research article on Prevalence of Musculoskeletal Dysfunctions among Indian Pregnant Women, by PreethaRamchandraet al, was published in 2014. Among other MSK dysfunctions the article also mentioned that pain in the knee joint is more prevalent than the ankle \& hip joint pain in pregnancy. It also states the pain to be most prevalent in the third trimester.

4) According to study conducted by Butler EE et al, on Postural Equilibrium during Pregnancy: Decreased Stability with Increased Reliance on Visual Cues, it was found that postural stability declines during pregnancy and remains diminished upto 6 to 8 weeks post delivery. 12 pregnant women \& 12 nulligravid women took part in the study. Subjects were asked to stand quietly on a stable force platform for 30 seconds with eyes open and closed. Path length and average radial displacement were computed on the basis of the average of 3 trials for each condition. The difference between the eyes open and closed values of path length increased as pregnancy progressed.

5) RosiFouladi carried out a study on Sex Hormones \& Neuromuscular Control System, in Iran. The JPS was measured 3 times a month with different level of sex hormones. It was evaluated by reproduction of the target angle ( $30^{\circ}$ flexion of knee) in standing position and absolute angular error (AAE) was considered as a dependent variable. The main observation of the study was that higher value of reposition error was found during the menses.

\section{Material and Methodology}

- Study Design: Cross Sectional

- Study Setting: Dr.D.Y.Patil Hospital, Navi Mumbai

- Population Of Study: Pregnant Women

- Ethical clearance: The Ethical clearance for the study was taken from the Institutional Ethics committee of Dr. D. Y.Patil University, Nerul, Navi Mumbai.

\section{Procedure}

The face and content validity of the topic was checked by experts (senior faculty from the School of Physiotherapy, D.Y.Patil University, Navi Mumbai, India) and their valid suggestions were accepted and implemented after discussion.

Testing of knee joint position sense: subjects were seated on a chair with hip \& knee at 90 degrees flexion. The inclinotrac was put on the distal thigh $\&$ at the upper $1 / 3^{\text {rd }}$ of the dominant leg.the leg was then taken into full knee extension passively by the examiner as the starting position \& then the subject was instructed to close her eyes. The examiner then passively moved the knee into 30 degrees of knee flexion \& kept it fixed for 10 seconds. The examiner then took the knee back to the starting position \& the subject was asked to reposition the knee to the same angle with eyes closed. The same procedure was repeated for 60 degrees of knee flexion. Three readings were recorded for each subject at both angles of knee flexion \& the mean value was considered for statistical analysis.

\section{Results}

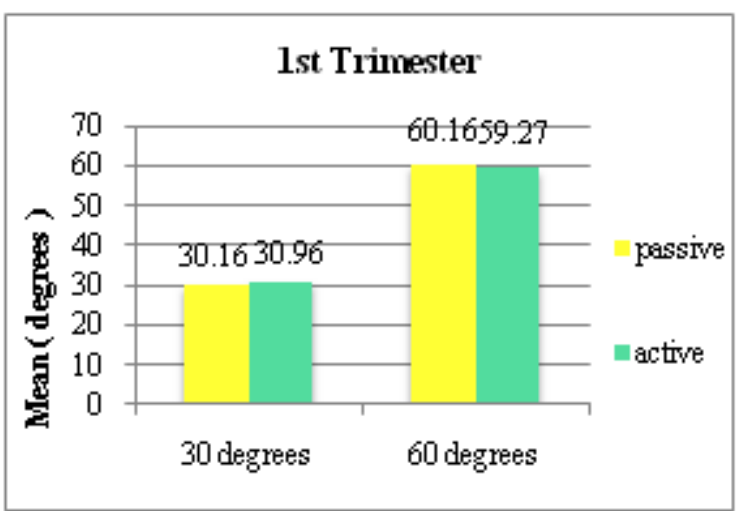

Figure 1: 30 degree and 60 degree passive and active (mean)

Table 1

\begin{tabular}{|c|c|c|c|}
\hline \multirow{2}{*}{} & \multirow{2}{*}{ Mean \pm S.D } & \multicolumn{2}{|c|}{$\begin{array}{c}\text { Confidence Interval } \\
\text { for Mean }\end{array}$} \\
\cline { 3 - 4 } & & $\begin{array}{c}\text { Lower } \\
\text { Bound }\end{array}$ & $\begin{array}{c}\text { Upper } \\
\text { Bound }\end{array}$ \\
\hline 30 degree passive & $30.16 \pm 0.34$ & 29.36 & 30.66 \\
\hline 30 degree active & $30.96 \pm 1.94$ & 27.74 & 34.87 \\
\hline 60 degree passive & $60.16 \pm 0.25$ & 59.83 & 60.65 \\
\hline 60 degree active & $59.27 \pm 3.50$ & 54.72 & 67.45 \\
\hline
\end{tabular}

The above figure 1 and table 1 shows mean values of passive $\&$ active repositioning of the women in their first trimester.

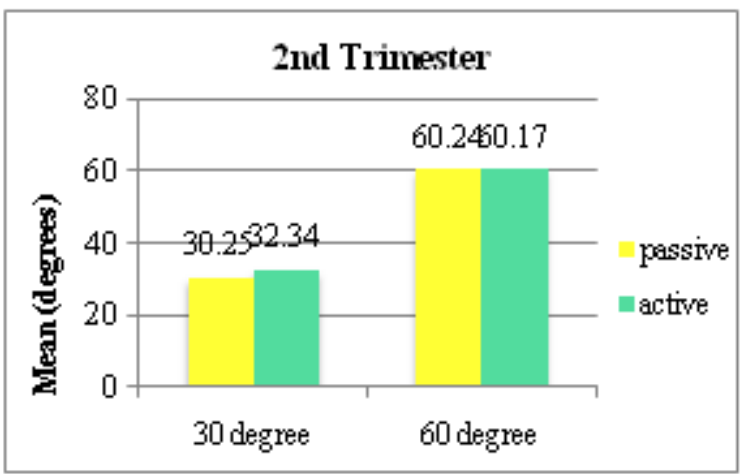

Figure 2: 30 degree and 60 degree passive and active (mean)

Table 2

\begin{tabular}{|c|c|c|c|}
\hline \multirow{2}{*}{} & \multirow{2}{*}{ Mean \pm S.D } & \multicolumn{2}{|c|}{$\begin{array}{c}\text { 95\% Confidence } \\
\text { Interval for Mean }\end{array}$} \\
\cline { 3 - 4 } & & $\begin{array}{c}\text { Lower } \\
\text { Bound }\end{array}$ & $\begin{array}{c}\text { Upper } \\
\text { Bound }\end{array}$ \\
\hline 30 degree passive & $30.25 \pm 0.16$ & 30.14 & 30.36 \\
\hline 30 degree active & $32.34 \pm 4.82$ & 25.19 & 38.99 \\
\hline 60 degree passive & $60.24 \pm 0.18$ & 59.97 & 60.51 \\
\hline 60 degree active & $60.17 \pm 7.88$ & 42.86 & 69.89 \\
\hline
\end{tabular}

The above figure 2 and table 2 shows mean values of passive $\&$ active repositioning of the women in their second trimester. 
International Journal of Science and Research (IJSR)

ISSN (Online): 2319-7064

Index Copernicus Value (2013): 6.14 | Impact Factor (2015): 6.391

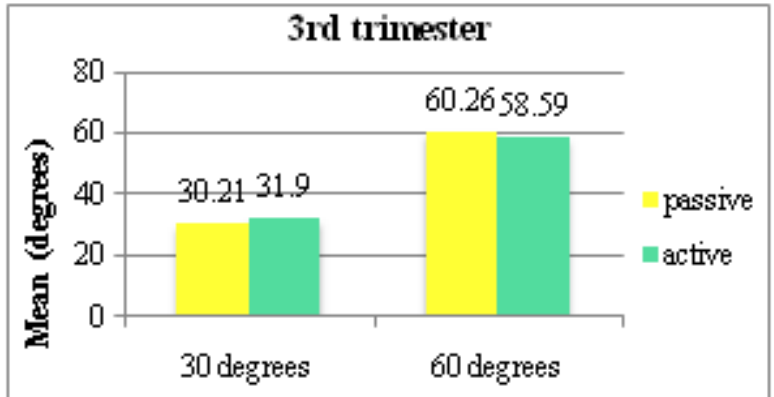

Figure 3: 30 degree passive and active (mean) 60 degree passive and active (mean)

Table 3

\begin{tabular}{|c|c|c|c|}
\hline \multirow{2}{*}{} & \multirow{2}{*}{ Mean \pm S.D } & S5\% Confidence Interval for Mean \\
\cline { 3 - 4 } & Lower Bound & Upper Bound \\
\hline 30 degree passive & $30.21 \pm 0.23$ & 29.86 & 30.51 \\
\hline 30 degree active & $31.90 \pm 4.35$ & 23.66 & 38.42 \\
\hline 60 degree passive & $60.26 \pm 0.29$ & 59.48 & 60.60 \\
\hline 60 degree active & $58.59 \pm 4.91$ & 53.75 & 67.48 \\
\hline
\end{tabular}

The above figure 3 and table 3 shows mean values of passive $\&$ active repositioning of the women in their third trimester.

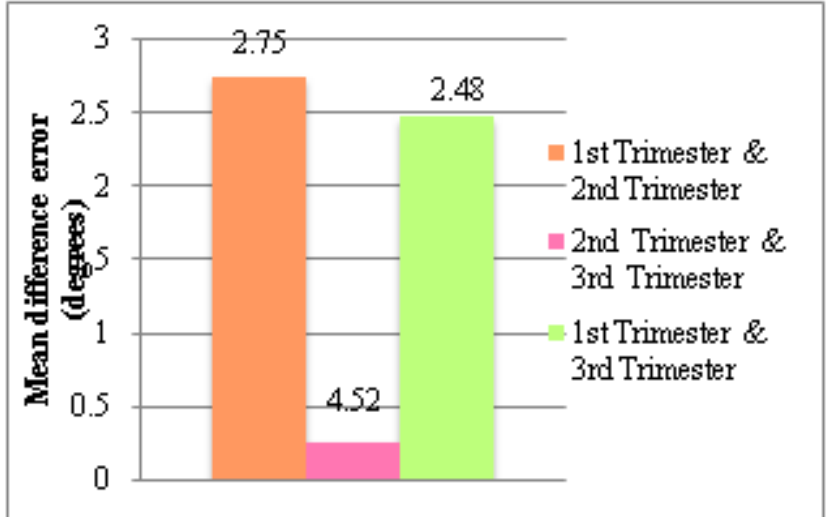

Figure 4: Comparison of mean difference of target angle error at 30 degrees $--1^{\text {st }}, 2^{\text {nd }} \& 3^{\text {rd }}$ trimester

Table 4

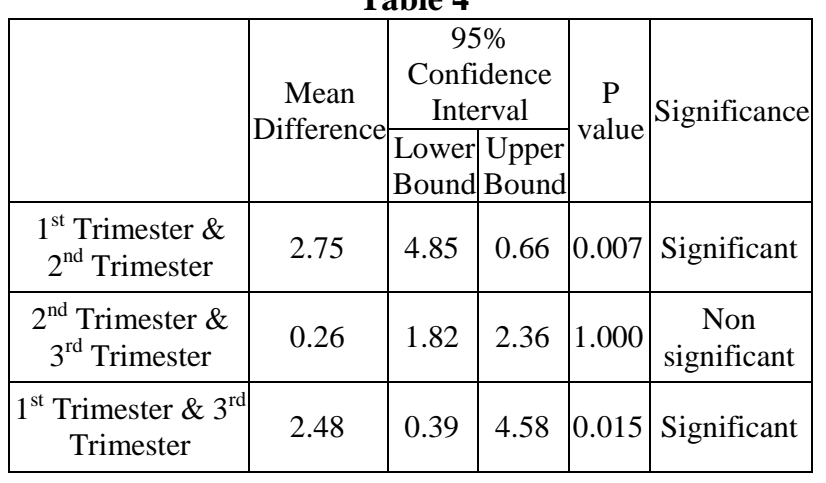

The above figure 4 and table 4 shows that the active repositioning error at 30 degrees was found to be statistically significant between $1^{\text {st }} \& 2^{\text {nd }}$ trimester as well as $1^{\text {st }} \& 3^{\text {rd }}$ trimester. While the error between $2^{\text {nd }} \& 3^{\text {rd }}$ trimester was found to be statistically non-significant.

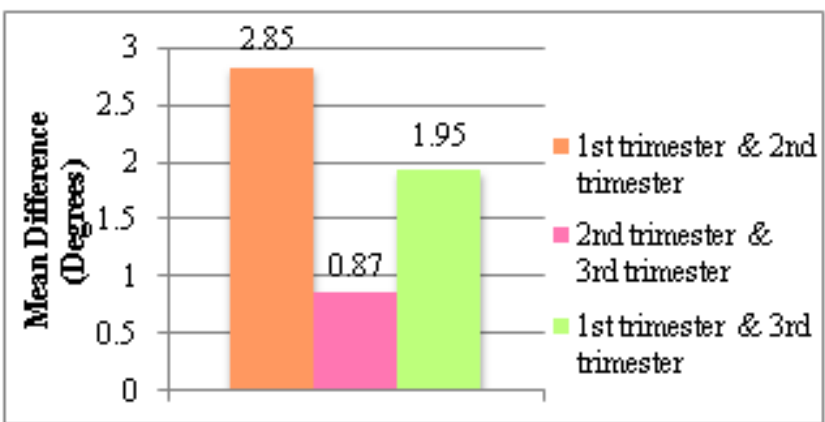

Figure 5: Comparison of mean difference of target angle error at 60 degrees $--1^{\text {st }}, 2^{\text {nd }} \& 3^{\text {rd }}$ trimester

Table 5

\begin{tabular}{|c|c|c|c|c|c|}
\hline & Mean & $\begin{array}{r}9 \\
\text { Conf } \\
\text { Inte }\end{array}$ & $\begin{array}{l}\% \\
\text { idence } \\
\text { arval }\end{array}$ & P & Significance \\
\hline & & $\begin{array}{l}\text { Lower } \\
\text { Bound }\end{array}$ & $\begin{array}{l}\text { Upper } \\
\text { Bound }\end{array}$ & & \\
\hline $\begin{array}{l}1^{\text {st }} \text { Trimester \& } \\
2^{\text {nd }} \text { Trimester }\end{array}$ & 2.82 & 5.46 & 0.18 & 0.03 & Significant \\
\hline $\begin{array}{c}2^{\text {nd }} \text { Trimester \& } \\
3^{\text {rd }} \text { Trimester }\end{array}$ & 0.87 & 1.76 & 3.51 & 1.000 & $\begin{array}{c}\text { Non } \\
\text { significant }\end{array}$ \\
\hline $\begin{array}{l}1^{\text {st }} \text { Trimester \& } \\
3^{\text {rd }} \text { Trimester }\end{array}$ & 1.95 & 0.69 & 4.59 & 0.21 & $\begin{array}{c}\text { Non } \\
\text { significant }\end{array}$ \\
\hline
\end{tabular}

The above figure 5 and table 5 shows that the active repositioning error at 60 degrees was found to be statistically significant between $1^{\text {st }} \& 2^{\text {nd }}$ trimester. While the error between $2^{\text {nd }} \& 3^{\text {rd }}$ trimester as well as the $1^{\text {st }} \& 3^{\text {rd }}$ trimester was found to be statistically non-significant.

\section{Discussion}

The mean age of the women included in this study was 25.11 \pm 3.16 years.

We hypothesized that knee proprioception decreases amongst pregnant women during the subsequent months of pregnancy. Our study confirmed this. The study was done to find the error repositioining of knee flexion during the three trimesters of pregnancy at 30 \& 60 degrees respectively.

According to graph4, it was found that at 30 degrees, there was a statistical significant decrease in the knee proprioception between the $1^{\text {st }} \& 2^{\text {nd }}$ trimester and the $1^{\text {st }}$ and $3^{\text {rd }}$ trimester, while the difference between the $2^{\text {nd }}$ and $3^{\text {rd }}$ trimester reduction was not found to be statistically significant. According to graph 5, at 60 degrees, it was found that there was a statistical significant decrease in the knee proprioception between the $1^{\text {st }}$ and $2^{\text {nd }}$ trimesters of pregnancy while the difference in mean error between the $1^{\text {st }}$ and $3^{\text {rd }}$ trimester as well as $2^{\text {nd }}$ and $3^{\text {rd }}$ trimesters was found to be statistically non-significant.

The reason for the above findings could be as follows:

\section{Postural Changes}

Proprioception is necessary in producing smooth and coordinated movements, maintaining normal body posture, regulating balance and postural control and influences motor learning. Proprioceptive signals are primarily generated by 


\section{International Journal of Science and Research (IJSR) \\ ISSN (Online): 2319-7064 \\ Index Copernicus Value (2013): 6.14 | Impact Factor (2015): 6.391}

receptors named muscle spindles. Mechanoreceptors which are special sensory receptors also play a role in proprioception. They transduce the mechanical events as frequency modulated neural signals to the Central Nervous System, through the afferent sensory pathway ${ }^{1}$ which are further used to build up an internal reference frame of the musculoskeletal system (body schema) and to recalibrate it $^{12,13}$ and thus form a useful kinesthetic sensation to interpret the proprioceptive signals within a reference frame. ${ }^{14}$

Postural adaptations during pregnancy include increased lumbar curvatures and pelvic inclinations, reduction of the dissociations between the movements of the pelvis and trunk, knee valgus misalignments, and possible reduction in the height of the longitudinal arch of the foot.All of these lower limb postural changes have found to result in postural instability, ankle plantar flexion and lower limb proprioception to decrease. ${ }^{15}$ Studies have revealed that during pregnancy postural instability is a frequent symptom of the second as well as third trimester at $12.12 \%$ and $14.81 \%$ respectively. Tendency to fall is also reportedly increased during the third trimester at $11.11 \%$. These complaints are supported by a study that states there is a greater anterior-posterior oscillation amongst pregnant women in the third trimester when compared to those in the first trimester, thus explaining the reduction in balance. ${ }^{16}$ Also, the lower limb joints are overloadedduring pregnancy due to the postural realignment during pregnancy, caused by increased body mass which is approximately 12 $16 \mathrm{~kg}$ and the superior and anterior displacements of the center of gravity. This further decrease in postural stability of pregnant women has been found to affect balance and the control of movements increasing the risk of falls during this period. ${ }^{15}$ These changes result in compensatory adaptations of the body causing loss of independence to perform daily living activities such as bending down to pick objects, climbing stairs and even walking; with increased knee loads observed during sit to stand. These all factors could be the possible reasons for knee proprioception error to be more significant at 30 degrees knee flexion angle than at 60 degrees knee flexion angle as found in our study.

\section{Hormonal changes}

Proprioception depends upon the somatosensory system, visual system and vestibular system. During pregnancy, hormonal alterations have been found to cause changes in the homeostasis of labyrinthine fluids, which have a direct influence on the enzyme process and the action of neurotransmitters. Additionally, estrogen and progesterone are often associated with vestibular affections such as dizziness, vertigo, instability. A recent study reported correlations between hormonal alterations and vertigo. Another study stated that during the first trimester the most frequent symptom associated with the vestibular system is dizziness due to vertigo (22.72\%), possibly stemming from hormonal alterations. ${ }^{16}$ During pregnancy, changes in knee proprioception could be attributed to the variation of the serum relaxin hormone. Levels of relaxin are found to be elevated during pregnancy. Studies demonstrate that during pregnancy ten fold increase in relaxin may occur which has a wide range effect on the connective tissues present in the body. It is associated with remodelling of collagen fibres which activates fibroblasts to synthesise new collagen fibres. The net effect of relaxin results in ligament laxity and weakening of soft tissue structures thus contributing to a decrease in proprioception. ${ }^{15}$

\section{Affection of Proprioception}

Studies have found that during pregnancy knee joint pain is more prevalent than the ankle and hip joint pains, more during the third trimester of pregnancy as compared to the second and first trimesters. ${ }^{6}$ Position sense at the knee joint is influenced by central \& peripheral mechanisms such as muscles, tendons, articulate, cutaneous and ACL receptors. The anterior cruciate ligament (ACL) in the knee contains estrogen receptors. This ligament has two complementary functions: mechanical and sensory (proprioceptive). Evidence suggests that an increase in estrogen levels affects the ACL ligament, such that the tensile properties of the ligament decrease, causing laxity of the ligament which has been reported to occur primarily during the second half of pregnancy with affection of muscles around the knee joint as pregnancy progresses. It has also been found that knee laxity increases on an average of $105 \%, 128 \%$ \& $170 \%$ during the first, second \& third trimesters of pregnancy respectively. ${ }^{1}$ Joint pain and altered muscle activity in combination with an inadequate ligamentous tension resulting from narrowing joint space have been shown to contribute to the interruption in the afferent signals for proprioception and neuromuscular control. ${ }^{17}$ Studies have revealed, a weaker proprioceptive perception of the anterior-posterior direction of tibia at the knee joint was detected. ${ }^{18}$ In addition to this loss of capsuleligamentous stability, it has been shown that proprioceptive deficits result of inadequate activation of mechanoreceptors leading to delayed muscle reaction latencies. ${ }^{17}$ There is a loss of neuromuscular control resulting from damage to the mechanoreceptors within the capsuloligamentous structures of the joint and from interruption to the afferent sensory pathways that play a crucial role in producing smooth coordinated movement. ${ }^{17}$ Also, as a response to relaxin, ligaments and other connective tissues lengthen resulting in reduced joint stabilty. Instability along with shift of center of gravity during pregnancy reduces neuromuscular coordination and balance which in turn causes a decreases in proprioception. ${ }^{19} \mathrm{~A}$ decrease in the plantar flexion and the propulsion forces have been found to result in longer step lengths and widths and greater anterior-posterior and medial-lateral sways ${ }^{12}$ altering balance and postural control especially in the $2^{\text {nd }} \& 3^{\text {rd }}$ trimester of pregnancy. This postural sway has been found to increase over the three trimesters of pregnancy. ${ }^{1,10}$ thus increasing reliance on visual cues to maintain balance further suggesting a decrease in proprioception. $^{1,10,20}$

Thus, this could also explain the decrease in proprioception with the advancement of pregnancy.

\section{Conclusion}

Evidence presented by this investigation demonstrates that the knee joint position sense was found to decline over the three trimesters of pregnancy, with a statistical significant difference between the $1^{\text {st }}$ trimester and $2^{\text {nd }}$ trimester and the $1^{\text {st }}$ and $3^{\text {rd }}$ trimester at 30 degree knee flexion angle. While a statistically significant difference was found between the $1^{\text {st }}$ trimester and $2^{\text {nd }}$ trimester at 60 degree angle of knee flexion. 


\section{International Journal of Science and Research (IJSR) \\ ISSN (Online): 2319-7064 \\ Index Copernicus Value (2013): 6.14 | Impact Factor (2015): 6.391}

\section{Future Implications}

1) Studies should be done considering women over their complete 9 month gestational period in order to better understand the exact pattern of the proprioceptive deficit found among women during pregnancy.

2) Studies with larger sample size should be undertaken in order to apply over a larger population.

\section{Acknowledgments}

The authors acknowledge all our study subjects deserve a word of thanks for their co-operation.

\section{References}

[1] Defne Kaya. Proprioception: The Forgotten Sixth Sense. Proprioception and Gender. Foster City, USA: OMICS Group eBooks; 2014 Aug.

[2] Ribeiro F, Oliveira J: Biomechanics in Applications. Factors Influencing Proprioception: What Do They Reveal? InTech; 2011 Sep.

[3] Rose Fouladi. Sex Hormones. Sex Hormones and Neuromuscular Control System. InTech; 2012 Feb

[4] Nagai T, Sell TC et al. Reliability, precision, and gender differences in knee internal/external rotation proprioception measurements. Phys Ther Sport. 2012 Nov; 13(4): 233-237.

[5] B.L Riemann, S.M Lephart. The Sensorimotor System, Part I: The Physiologic Basis of Functional Joint Stability. J Athl Train. 2002 Jan-Mar; 37(1): 71-79.

[6] P. Ramachandra, A G Maiya, et al. Prevalence of Musculoskeletal Dysfunctions among Indian Pregnant Women. J Pregnancy. 2015

[7] T.Foti, J.R.Davids, et al. A Biomechanical Analysis of Gait During Pregnancy. J Bone Joint Surg Am. 2000 May; 82(5): 625-632.

[8] H.M Hahn. The Effect of Sex Differences and Hormone Fluctuation on Ankle Stability and Function. Theses and Dissertations. 2009; 1067.

[9] Faryniarz DA, Lajam C, et al. Quantitation of Estrogen Receptors and Relaxin Binding in Human Anterior Cruciate Ligament Fibroblasts. In Vitro Cell Dev Biol Anim.2006 Jul-Aug; 42(7): 176-181.

[10] Preetha R, John M. Comparison of Ankle Proprioception Between Pregnant and Non Pregnant Women. Online J Health Allied Scs. 2011 Apr-Jun; 10(2): 9.

[11] Dunning K, LeMasters G, et al. A Major Public Health Issue: The High Incidence of falls during Pregnancy. Matern Child Health J. 2010; 14(5): 720-725.

[12] Lackner J, DiZio P. Vestibular, Proprioceptive, And Haptic Contribution To Spatial Orientation. Annu Rev Psychol 2005; 56: 115-147.

[13] Sainburg R, Ghez C, Kalakanis D. Intersegmental Dynamics Are Controlled By Sequential Anticipatory, Error Correction, And Postural Mechanisms. J Neurophysiol 1999; 81: 1045-1056.

[14] Gurfikel V, Levik I. Reference Systems And Interpretation Of Proprioceptive Signals. Hum Physiol 1998; 24: 46-55.

[15] A.P Ribeiro, et al. Static and Dynamic Biomechanical Adaptations of the Lower Limbs and Gait Pattern
Changes During Pregnancy. Women's Health. 2013; 9(1): 1-10.

[16] P.M Schmidt, F.T Flores et al. Hearing and Vestibular Complaints During Pregnancy. Btaz J Otorhinolaryngol. 2010; 76(1): 29-33.

[17] J. Andrews, G.L Harrelson et al. Physical Rehabilitation of the Injured Athletes. $4^{\text {th }}$ ed. Philedelphia PA. Elsevier Saunders. 2012.

[18] T. Banyai, A. Haga, et al. Knee Joint Stiffness and Proprioception During Pregnancy. J Orthopedics. 2009; 1: 29-32.

[19] Jill Mantle. Physiotherapy in Obstetrics \& Gynecology. Physiology of Pregnancy. $2^{\text {nd }}$ ed. ButterworthHeinemann. 2011 May.

[20] Butler EE, Colon I et al. Postural Equilibrium During Pregnancy: Decreased Stability With an Increased Reliance on Visual Cues. Am J Obs and Gynae. 2006 Nov; 195(4): 1104-1108.

\section{Author Profile}

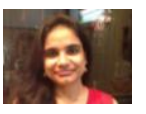

Dr. Deepa Abichandani is an Assistant Professor in Physiotherapy from School of Physiotherapy, Dr DY Patil University. She specializes in Musculoskeletal and rehabilitative aspects of Physiotherapy. She also takes special interests in areas of Preventive and Community Based Rehabilitation

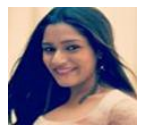

Dr Vanshika Gupta is currently a practising physiotherapist. She has keen interest in Women's Health. She intends to work towards improving regimes in field of Women's Health and Fitness. 